\title{
Does the Medium Matter? Linking Citizens' Use of Communication Platform for Information about Urban Policies to Decision to Trust in Local Government
}

\author{
Hyunkuk Lee
}

Department of Public Administration, Daejeon University, Daejoen 34520, Korea; hyunkuklee@gmail.com

Citation: Lee, H. Does the Medium Matter? Linking Citizens' Use of

Communication Platform for Information about Urban Policies to Decision to Trust in Local Government. Sustainability 2021, 13, 2723. https://doi.org/10.3390/ su13052723

Academic Editor: Jean-Pierre Gueyie

Received: 29 January 2021

Accepted: 18 February 2021

Published: 3 March 2021

Publisher's Note: MDPI stays neutral with regard to jurisdictional claims in published maps and institutional affiliations.

\begin{abstract}
Information plays a formative role in citizens' decision to trust their government. Given an increasingly diverse information environment, which is attributable to the diffusion of information and communication technologies (ICT)s, the Internet, and social media, we hypothesize that citizens' use of a particular medium for information (online vs offline, and government source vs. nongovernment source) about their government plays an important and distinctive role in shaping citizens' satisfaction with government information provision and trust in government. To address this central hypothesis, we analyze data from the 3068 citizen respondents. The findings of our study reveal that citizens' use of the online medium for information about their government, such as information from local government web-media, lacks a strong relationship with their levels of satisfaction with government information provision and trust in government, while citizens' use of different sources on the offline medium for information about their government, such as information from local government meeting or official gazette, is found to have a stronger association with citizens' trust in government and satisfaction with government information provision.
\end{abstract}

Keywords: trust in government; information; citizen satisfaction; ICT

\section{Introduction}

The increasing sophistication and diffusion of the Internet, social media and information and communication technology (ICT) into society has led many to believe that the way in which government information is disseminated to citizens may be undergoing fundamental changes [1-3]. For this reason, many scholars have begun to argue that the Internet and social media are restructuring citizen-state relationships, while the proliferation and increasingly widespread usage of terms such as e-government, e-democracy, e-participation, and the virtual state indicates they may be right $[4,5]$. These changes to the information climate have been occurring within a broader social context of consistently reducing levels of trust in government and an increasingly unsatisfied public [6,7] (This research focuses in particular upon trust in government in South Korea, where evidence suggests that trust has indeed been declining over the past decade. In addition, a great deal of literature related to the United States has suggested that trust in government has been declining for some time. However, research by Van de Walle, Van Roosbroek, and Bouckaert [8] argue little evidence exists to suggest that trust in government, at least among European nations, has steadily declined over time. Instead, they argue that levels of trust have been fairly consistent, but do oscillate). As such, this new technology has been championed by academics and practitioners as a means of heading off these ostensibly bleak trends by empowering government to better serve its citizens and foster greater interaction given the Internet's potential to solicit greater citizen participation, facilitate more diffuse consumption of information, and at less of a cost to citizens and government $[9,10]$. To this end, projects have been pursued by governments around the world to harness the power of the Internet in order to help transform the increasingly negative opinions of citizens. Among the most well-known examples of such projects is the United States' Open Government 
Directive, which sought to use the Internet as a means of improving relationships between citizens and the state [11,12].

However, the Internet's effects on information dissemination are not only changing the way governments interact with citizens. Rather, the Internet has also been adopted by private, non-government actors, which has stimulated the creation of a variety of new non-government channels of government information dissemination ranging from social media, to 'wikis', to political blogs, to online newspapers. Furthermore, the use of the Internet as a means of information dissemination dramatically lowers the cost of disseminating information for citizens and non-government actors, which has led to a "power shift" according to Jessica Mathews, who claims that the "instantaneous access to information and the ability to put it to use multiplies the number of players who matter and reduces the number who command great authority". As explained by Mathews, the diversity of government information online is expanding and gaining a variety of new attributes, which in turn may serve to engender the information government transmits via the online medium with a distinctive impact on citizens' trust in government vis-à-vis the offline medium. However, the impact that citizens' use of these different information mediums - online versus offline- - has on their trust in government and satisfaction remains largely unstudied. Given this dearth in the available literature the objective of this research is to take an initial step in addressing this void by examining how government's use of online and offline mediums of information dissemination affect citizens' satisfaction with government information provision and levels of trust in government. With our survey data analysis from 3068 citizen respondents, we aims to link citizens' use of communication platform for information about urban policies including urban sustainability initiatives to their decision to trust in local government.

\section{Theoretical Framework}

\subsection{Trust in Government}

A substantial amount of scholarly resources throughout the social sciences have been dedicated toward deriving a better understanding of the factors that influence citizens' decision to trust [13-16]. As Kramer and Lewicki point out, "given the diversity of disciplinary attention that has been afforded to the topic, it is hardly surprising that a plethora of distinct, and not always compatible, conceptions of trust have been proffered by scholars". Acknowledging the diversity found throughout the breadth of trust literature, Rousseau and colleagues [17] have attempted to synthesize the diverse understandings of trust in order to "give fundamental insight into a fundamental construct". Based upon the common elements of trust they identified, Rousseau and colleagues [17] define trust as, "a psychological state comprising the intention to accept vulnerability based upon positive expectations of the intentions or behavior of another". Following the definition provided by Rousseau and colleagues [17], trust can be seen as premised upon the presence of positive expectations and intentions to accept vulnerability [18,19].

The intention to accept vulnerability relates to one actor's (trustor) dependence upon another (trustee) for a future task. Here, intention to accept vulnerability is heavily influenced by the information the trustor possess about the trustee and the particular task that forms the basis of the relationship between the trustor and trustee [20,21]. Put differently, the trustor's willingness to accept vulnerability to the trustee is contingent upon the trustor's perception of risk related to depending upon the trustee [18]. In the event that the trustor positively evaluates the risks associated with depending upon the trustee for a future task as acceptable and accepts vulnerability, it is generally concluded that various features of the trustor have contributed toward fostering their positive expectations of the trustee $[15,21]$. Positive expectations can be seen as akin to the trustor's positive perception of the trustee's trustworthiness [22,23].

Trustworthiness can be divided into components of perceived ability, perceived benevolence and perceived integrity of another [13]. Ability refers to the capacity of the trustee to fulfill a task for which they are responsible for. Here, the trustor must perceive the 
trustee as possessing the necessary skill set to carry out the task they are entrusted with. Benevolence refers to the trustor's perception that the trustee will put the needs of the trustor above their own in order to complete a particular task, if necessary. For example, the trustee will not engage in behavior that would violate the interests of the trustor, should an incentive for doing so be construed by the trustee. The final dimension, integrity, suggests that the trustor perceives the trustee as possessing a compatible set of ethics. To this end, the integrity dimension may be seen as overlapping to some degree with the benevolence dimension.

In this study, the trustor refers to Seoul citizens whereas the trustee refers to the Seoul Metropolitan government. Previous literature has argued that citizens' perceptions of government should be refined and assessed according to micro, meso, and macro levels as doing so will allow more accurate insight into the antecedents of said perceptions $[20,24]$.

The first 'micro' level of government can be considered as individuals responsible for the delivery of public services, such as "street level bureaucrats", policemen, or firefighters [25-27]. The second 'meso' level of government concerns particular organizations and institutions associated with the delivery of specific public services, such as police or the Internal Revenue Service. Hence, trust in these two levels of government may be more sensitive to performance with respect to public service provision [28,29], vary across policy area and institutions, and as such constitute more of a specific percpetion of government [20,30].

The third macro level of government is more of an abstract, affective and general conceptualization of government. At this level, government is viewed as an embodiment of principles and social values and norms. Citizens' decisions to trust government are contingent upon their general assessments of the direction their government is leading them in [31]; "it is not a matter of doing things well, but of doing good things" [20]. Citizens' distinction between doing good things and doing bad things is likely to be conditioned by the dynamics of the context citizens are making trusting decisions in [24,32]. Keeping in mind the characteristics of this level of government, trust in this third level of government is less discerning and more diffuse [20,33,34].

In assessing the the impacts of online and offline mediums of information dissemination on citizens' levels of trust in government this research focuses in particular upon the third macro level of government. This is because this research is interested in examining potential differences in the way citizens' use of online and offline information mediums serve to affect their diffuse dispositions toward government as a concept, rather than specific elements of government, such as the office of the president, the military or public transportation services (It is also possible to distinguish between political trust and public sector trust, or "government as politics" and "the public sector" [12,20]. This study uses survey questions based off of those used in the National Election Survey. These questions do not differentiate between political trust and trust in the public sector. Therefore, we do not emphasize the distinction in the literature review). Finally, if meso or micro levels of government were to be assessed, various specific measures of performance should be introduced, but doing so may introduce a degree of conceptual confusion regarding trust and take away from the central objective of this research.

\subsection{Citizen Satisfaction with Government Information Provision}

Just as many believe the government should provide citizens with education, transportation or water, it is generally believed that the public sector must also keep citizens informed of its various activities $[35,36]$. As such, government information provision can be considered a public service. Throughout the field of public management, citizens' satisfaction with public services and trust in government are linked [24,37]. This link between citizens' levels of public service satisfaction and trust in government has been referred to as the performance hypothesis [20,38], where higher levels of satisfaction are argued to lead to higher levels of trust in government. While this relationship has been criticized for 
being overly deterministic (i.e., [31]), to date there exists ample evidence supporting the validity of this performance hypothesis $[6,39,40]$

Citizens' satisfaction with government information provision can be seen as speaking to citizens' perception that the public sector provides citizens with sufficient, honest and accurate information regarding its activities (cf. [12]). Citizens' satisfaction with government information provision can influnce their perceptions of government trustworthiness [41,42]. First, citizens' satisfaction with government information provision can lead them to believe that their government is being honest with them and not attempting to hide anything; previous research has suggested that information asymmetries are negatively related to trust in government [43]. Accordingly, satisfaction with government information provision may also lead citizens to feel that their public sector is willing to be held accountable and therefore attempting to act in the best interests of citizens [44]. Consequently, citizens may be more willing to accept vulnerability. Second, citizens' satisfaction with government information can improve citizens' perceptions of the public sector's capacity to fulfill its various functions. Swindell and Kelly [45] has argued that citizens' lack of satisfaction with the way their public sector is performing is often due to a lack of accurate information. Indeed, previous literature has suggested that significant disparities exist between citizens' subjective evaluations of how public services are running and more objective measures [46,47]. As a result, citizens who are better informed of their public sector evaluate their public sector's skill set and performance more positively than those who are poorly informed [48,49]. Citizens who are more satisfied with government information provision are likely to be better informed than those who are less satisfied with government information provision.

It is also possible that citizens' levels of trust in government influences their levels of satisfaction with information provision. For example, it may be that citizens' levels of trust in government may lead them to feel that their government is being completely open and that they "know enough". Yet, conceptually, as was explained earlier citizens' decision to trust their government is contingent upon their willingness to accept vulnerability to their government. Previous research has argued that citizens' willingness to accept vulnerability is contingent upon the decision that the information accumulated by the trustor (citizens) regarding the trustee (government) is sufficient. As Bouckaert and colleagues [20] write, the decision to extend trust (and accept vulnerability) "depends on a choice: at a certain moment there is a (socially defined) decision not to take any further evidence or rational reasons" (If citizens feel they do not possess adequate information than trust will not be extended). Citizens' decision to stop looking for "further evidence or rational reasons" (information) related to their government and subsequently trust their government can thus be seen as stemming from their satisfaction with government information provision (While a conceptual justification for the order or relationships between satisfaction and trust is provided in this paragraph a discussion of this issue from an empirical perspective is provided in the methods section).

Based upon the arguments outlined above, citizens' satisfaction with government information provision is likely to positively influence their perceptions of the ability, benevolence and integrity dimensions of government trustworthiness and make them more willing to become vulnerable to their government. As such, Hypothesis 1 is outlined as follows:

Hypothesis 1 (H1). Citizens' satisfaction with government information provision is positively related to their levels of trust in government.

\subsection{Antecedents to Satisfaction with Government Information Provision: The Medium}

Citizens' levels of satisfaction with public services are said to often be influenced not by experience with a particular service, but rather via third parties [50,51]. In this vein, a variety of different information sources have been argued to shape citizens' attitudes toward public services and government in general [3,52]. The development and diffusion of 
ICTs, such as the Internet has led to increased diversity in terms of the information mediums and sources citizens can (actively or passively) access to learn about what their government is doing. In response, governments around the world have been active in adopting the Internet as a means of keeping citizens better informed of what their government is doing, often times in hopes of improving citizens' attitudes toward their public sector $[53,54]$.

To be inferred from the trend described above is that public sectors have assumed that using the Internet and social media to provide citizens with information will improve their perceptions of this public service when compared to the conventional offline medium. However, despite widespread enthusiasm for government's use of the online medium to improve citizens' attitudes toward their government, such as satisfaction with government information provision [6,9], empirical support for such enthusiasm has been underwhelming. A possible explanation for this lack of support is that public sector online mediums of government information dissemination are simply not being used by a broad enough spectrum of citizens to make a difference due, at least in part, to characteristics of the medium. Several theories throughout the social sciences offer clues as to why this may be. Confirmation bias theory suggests that individuals will tend to use information that reinforces their extant beliefs [55]. As an extension of confirmation bias theory, selective media exposure theory proposes that individuals will exhibit a preference for media sources that align with their extant beliefs [56,57]. Subsequently, citizens who believe that public sector information provision is not satisfactory would likely seek out information sources online that align with that opinion. Therefore, such citizens would not be likely to be influenced by the public sector's presence on the online medium. In the e-government literature this is sometimes referred to as the reinforcement effect (Kraemer and King 2006).

Some have argued that the rapid expansion of the online medium and subsequent increase in diversity of information sources have served to magnify reinforcement effects because citizens who use the online medium to retrieve information about their public sector are now more likely to find sources that closely adhere to their extant opinions ([57] Stroud 2008). Therefore, due to its diversity citizens' use of the online medium of information dissemination to learn about their government is likely to have little positive influence upon levels of satisfaction with government information provision overall.

Hypothesis 2 (H2). Increased frequency of use of online medium of information provision will not be significantly related to their levels of satisfaction with government information provision.

The impact of citizens' use of the offline medium on their levels of satisfaction with government information provision is likely to differ from that of the online medium due to different characteristics of the two mediums. Specifically, while factors such as selective media exposure theory are also present in the offline medium [52,57], selective media exposure likely to be much less pronounced on this medium due to greater barriers to popular participation and limitations regarding the diversity of information disseminated [58].

The relative exclusivity of the offline medium may affect citizens' exposure to information about their government and satisfaction with government information provision in two distinct ways. First, citizens who make use of offline sources for information about their government will have fewer information sources from which to choose [59]. Given fewer information sources from which to choose from, citizens will tend to be exposed to a broader spectrum of information (from the limited number of public and private sources) that less perfectly overlaps with their own opinions [60]. Second, the opposite is also possible, whereby the relative exclusiveness of the offline medium permits elites to better control the information disseminated to the public, thus limiting citizens' exposure to a broader qualitative spectrum of information about their government. In this vein, Entman [61] has found that in traditional offline media environments, information dissemination related to government by 'independent' media outlets is heavily influenced by government elites, who determine what information is disseminated to journalists and other agents of mass media. In this case, citizens have access to a narrower spectrum of government information that is also less likely to closely align with their opinions regarding government, as citizens 
are primarily only exposed to the information government wants them to be exposed to (cf. [62]).

While the two affects outlined above can be seen as opposites, their influence upon citizens' levels of satisfaction with government information provision are likely to be the same. First, citizens' may be exposed to more moderate/balanced information via offline mediums as information sources in this medium attempt to appeal to a broader audience than online sources, which often cater to a niche audience [63-65]. Exposure to a broader spectrum of information has been found to leave citizens feeling better informed about their government than they would be had they only accessed information sources that closely aligned with their extant opinions on government [59]. This is likely to ring particularly true for those citizens who possess more negative attitudes toward government [3]. Second, in the event that government elites carefully filter information that makes its way public, citizens are likely to be heavily exposed to (more) positive information regarding their public sector $[12,66]$. In turn, this exposure can also translate into more positive attitudes toward the public sector and leave citizens feeling more satisfied with government information provision. Bearing in mind these points, it is likely that citizens' use of offline mass media will positively influence their levels of satisfaction with government information provision.

Hypothesis 3 (H3). Increased frequency of use of the offline medium of information provision will be positively associated with citizens' levels of satisfaction with government information provision.

\subsection{The Context of Seoul}

To explore the hypotheses outlined above we assess how citizens' use of online and offline information mediums affect satisfaction with government information provision and trust in government in Seoul, South Korea. Two reasons are provided. First, the city of Seoul possesses one of the most sophisticated and diffuse ICT infrastructures in the world $[3,67]$. As a result, both the Seoul Metropolitan government and citizens actively make use of technologies such as the Internet to exchange information and interact with each other frequently. Second, due to the high level of sophistication and diffusion of ICT in Seoul, citizens ability to interact with their government goes beyond the passive unilateral exchange of information to incorporate more participatory elements $[14,68]$. For example, cyber cafes on popular portal websites often provide forums in which citizens congregate to actively discuss current issues related to the government $[3,69]$. The information spread via these online forums and social media have been used to influence public policy on more than a few occasions $[47,70]$. The public sector has also created various online forums and social media platforms through which citizens can participate in and influence administrative processes [71,72].

Previous research has often suggested that the online medium is less interactive than the offline medium as the flow of information between actors online is much more unidirectional [2,9]. Based upon the explanation provided above, this particular point of distinction between the online and offline mediums is likely to be less pronounced in Seoul than elsewhere. Previous literature has often blamed governments for not effectively making use of the online medium to encourage greater participation with citizens and cited this as a reason that the online medium has fallen short of its transformative potential $[2,73]$. From a theoretical perspective, the similarities between these two mediums in Seoul permits a degree of insight into alternative theoretical perspectives as to the online medium may not be as effective in positively influencing citizens' attitudes toward their government as many have hoped.

The Seoul Metropolitan Government's urban policies have strong focus on urban sustainability infinitives [74], and they, for instance, has formulated Sustainable Development Vision, that include twelve strategies, twenty-eight tasks and thirty dedicated indicators - they are committed to implement the international sustainable development agendas and review the impact on urban governance and activities based on sustainability 
impact assessment [14]. In 2018, the Seoul Metropolitan Government also announced the Seoul Sustainable Development Goals that embody the city government's direction of development as a sustainable city with 17 major goals with 96 targets indicators-Seoul's plan includes various aspects of sustainability such as initiatives that reduce the concentration of fine dust to $70 \%$ and the generation of greenhouse gases to $40 \%$ responding to climate change, make sure that all citizens have access to safe and well-balanced food, receive quality education at a reasonable cost, and satisfy the basic needs of vulnerable social groups. Given the scale and scope of Seoul's sustainability plan, citizen's trust in government has been a core issue in urban policy discourse as the envisioned goals by Seoul can't be achieved without citizen's cooperation, compliance, and coproduction $[75,76]$.

\section{Methodology}

\subsection{Data}

Data used in this study comes from the Seoul Online Citizen Survey, which is administered by the Internet survey firm Embrain. 12,256 Seoul citizens who are registered with the Internet survey firm were invited to complete the survey. Proportional stratified sampling was used in order to ensure that our sample was representative of the population of Seoul. Parameters used include: residential district within the city, income, age (with the exception of 60+), gender., education and political affiliation. However, our sample was found to be unrepresentative of the population above 60 years old in Seoul due to a low response rate from this demographic category. In an attempt to address underrepresentation of this demographic an additional survey was administered specifically to this category. This supplemental survey that targeted the 60 and older demographic was administered. However, the response rate remained very low. Consequently, the underrepresentation of the 60 and older demographic of Seoul city remains a limitation of this research (Though frequently used in public administration research, online surveys are criticized for not be representative of the population of interest. For example, given the fact that they are administered online limits possible respondents to only those who possess a computer. Additionally, as online surveys often have low response rates, which may suggest further bias in terms of representativeness. These limitations may bias the sample on parameters such as income, education or, as was the case in this study, age).

Of the 12,256 survey respondents invited to reply, 3423 responded, while 355 surveys were deemed unusable as those responses were found to have missing responses in our outcome variable measures. Thus, a total of 3068 surveys were used to collect the data used in this research. With the exception of the 60 and older demographic underrepresented, this sample of Seoul citizens can be considered representative of the total population of Seoul citizens.

\subsection{Model}

While this study argues that citizens' satisfaction with government information provision will lead to higher levels of trust in government, it is also possible for citizens' levels of trust in government to lead to higher levels of satisfaction with government information provision $[6,43]$. Due to such concerns over simultaneity, this study uses a simultaneous equation model, which allows more accurate insight into the relationship between satisfaction with government information provision and trust in government, by controlling for the influence of trust in government on satisfaction with government information provision. This is done through the use of instrumental variables, which are strongly correlated with citizens' satisfaction with government information provision, but weakly associated with citizens' levels of trust in government. As such, a change in the instrumental variables should influence citizens' satisfaction with government information provision, but possess no direct impact upon citizens' trust in government. The impact of the instrumental variable on trust in government will be indirectly transmitted via the impact upon satisfaction with government information provision. A more technical explanation is provided below. 
To estimate satisfaction with government information provision's association with trust in government using a simultaneous equation, we first estimate an OLS Equation (1):

Trust in government $=\beta_{0}+\beta_{1}$ satisfaction for information provision $+X \beta+\epsilon$

$X$ represents a vector of control variables. $\beta_{1}$ represents the coefficient of satisfaction with government information provision and $\beta$ represents the coefficient vector of control variables, while $\epsilon$ represents the error term.

We estimate a second equation as follows, Equation (2):

Satisfaction with government information provision $=\beta_{0}+\beta_{1}$ trust in government + $\beta_{2}$ media use(IV) $+Z_{\gamma}+\omega$

In Equation (2), $Z$ refers to a vector of exogenous variabls, $\gamma$ refers to the coefficient vector of exogenous variables. $\omega$ refers to the error term. For this study, we use citizens' use of different sources of government information in the online and offline mediums as instrumental variables for satisfaction with government information. The reason that these variables are used is that they are likely to be closely related to citizens' satisfaction with government information provision, while citizens' use of online or offline mediums are unlikely to have a substantial direct influence upon levels of trust in government. The empirical validity of these instrumental variables was assessed using a Sargan test, which examines whether the residuals are correlated with the set of exogenous instrumental variables. If the instruments are truly exogenous, then the residuals of the equations specified above should be uncorrelated with the set of exogenous variables [77]. Our test statistics showed the instruments are exogenous. Harman's single factor test indicates that the common latent factor in our model doesn't seem to exist as the single factor doesn't accounts for large variance.

Finally, as was mentioned earlier, Equations (1) and (2) are endogenously related due to satisfaction with government information provision. To address this endogeneity, we can estimate a 2SLS (two stage least square) simultaneous equation. However, estimates produced by 2SLS are not more efficient than those produced by GLS (generalized least squares model), which assumes the variance of the error is autocorrelated and demonstrates heteroskedasticity. Therefore, a 3SLS model, which uses makes use of a GLS, in addition to 2SLS, produces more efficient estimates than a simple 2SLS alone [78]. As such, we use estimates provided by 3SLS.

\subsection{Measurement}

Key variables measured in our analytical model are citizens' trust in government, citizen expectations, citizens' use of online mediums of government information, and citizens' use of offline mediums of government information. Variables were measured using multiple items. These items were pilot tested before conducting the actual survey in order to discover and eliminate problems present in the survey instrument, such as difficult to understand or ambiguous questions. Summary statistics are shown in Table 1.

Survey respondents were asked to rate their responses according to a five or six point Likert scale. Use of data based on Likert scales is said to generate biased estimators and standard errors when analyzed using multiple regression analysis, as this research does [79]. The reason for this is that the Likert scale is not actually continuous, and as such results in a loss of information [80]. However, research by Owuor and Zumbo [81] has demonstrated that biases caused by using data based on Likert scales are most pronounced when models only contain two scale points, and noticeably diminishes when there are four scale points or more. As such, the results of research that makes use of data based on Likert scales should be interpreted with such potential biases in mind. 
Table 1. Summary Statistics.

\begin{tabular}{|c|c|c|c|c|c|}
\hline Variable & Observation & Mean & Std. Dev. & Min & Max \\
\hline Trust in local government & 3068 & 2.554 & 0.607 & 1 & 5 \\
\hline Satisfaction for information & 3016 & 2.422 & 0.768 & 1 & 5 \\
\hline Satisfaction for quality of service & 3077 & 3.798 & 0.885 & 1.042 & 6.583 \\
\hline Satisfaction for mayor & 3031 & 2.453 & 0.958 & 1 & 5 \\
\hline Expectation & 3077 & 4.236 & 1.211 & 1 & 7 \\
\hline Female & 3081 & 1.507 & 0.500 & 1 & 2 \\
\hline Age & 3077 & 39.027 & 11.291 & 18 & 70 \\
\hline District-Wealthy & 3077 & 0.138 & 0.345 & 0 & 1 \\
\hline Household income & 3081 & 3.942 & 1.529 & 1 & 6 \\
\hline Same party support with mayor & 3077 & 0.220 & 0.414 & 0 & 1 \\
\hline Religion & 3077 & 1.476 & 0.499 & 1 & 2 \\
\hline Government Gazette & 3077 & 1.558 & 0.975 & 1 & 6 \\
\hline Government Website & 3077 & 2.166 & 1.093 & 1 & 6 \\
\hline Government Web-media & 3077 & 2.185 & 1.284 & 1 & 6 \\
\hline Web-media & 3077 & 3.552 & 1.680 & 1 & 6 \\
\hline Neighborhood meeting & 3077 & 1.525 & 0.941 & 1 & 6 \\
\hline Government official meeting & 3077 & 1.297 & 0.774 & 1 & 6 \\
\hline TV News & 3077 & 4.098 & 1.682 & 1 & 6 \\
\hline Radio News & 3077 & 2.857 & 1.713 & 1 & 6 \\
\hline
\end{tabular}

Trust in government was measured by a standardized questionnaire developed by the Institute for Social Research (ISR) at the University of Michigan that was translated into Korean. This questionnaire is frequently used in research assessing trust in government [82-84] and corresponds to the dimensions of trustworthiness used in this study. The items ask survey respondents to rate on a scale of 1 , 'not at all', to 5 , 'very much', how much they agreed with the following five statements; (1) "Seoul city government wastes taxes", (2) "Seoul city government does the right things as a local government", (3) "Seoul city government works in the interest of some interest groups as opposed to the general public", (4) "Seoul city officials are very competent", and "Seoul city officials are corrupt". The Cronbach's alpha, used to measure the construct validity of these questions is 0.7519 , which is well above the commonly accepted threshold of 0.7.

Citizens' satisfaction with government information provision was measured by the following question; "Please rate your satisfaction on a scale of 1 to 5 , where 5 means 'Very Satisfied' and 1 means 'Very Dissatisfied' with the following aspects of communication provided by the Seoul Metropolitan Government". Following this question, survey respondents were given several items to rate; the two items that addressed citizen satisfaction with government information provision in particular were availability of information about city programs and services, and availability of information about city budget and financial information. The Cronbach's alpha of this two-item measure of citizen satisfaction with government information provision was 0.807 .

Citizens' use of online/offline mediums for government information was measured according to the following question, "Lately, how often have you used the following sources to get news about community issues and city policies and activities?" Survey respondents were asked to rate their use of various forms of online and offline media on a scale of 1 (never) to 6 (very often). A similar measure can be found in Welch et al. [43]. Online forms of information included in our study were city government website (includes e-government services and government social media, as well as a wealth of specific information regarding 
the city), local government web media (includes more general information pertaining to news of events occurring in the city), and non-government web media (non-government sources of Internet, such as Internet newspapers, social media and blogs). Offline forms of information included neighborhood meetings (groups of citizens who meet to discuss current events), local government official meeting (community meetings held by the government), a gazette printed by the city government, T.V. news (no particular channels were assessed), and radio news (no particular stations were assessed).

Finally, several variables that previous research has suggested may influence citizens' satisfaction with government information provision and trust in government were also provided. First, a fairly standard set of socio-economic variables were controlled for as variables such as income (individual and residential area), age, gender, education and religion have all been suggested to influence citizens' attitudes toward government $[85,86]$. Given the link between satisfaction and trust outlined earlier, different forms of satisfaction were controlled for-satisfaction with mayor's leadership, satisfaction with involvement in government and satisfaction with the quality of public services- in an attempt to further isolate the influence of citizens satisfaction with government information provision on trust in government. Similarly, a variable addressing citizens' expectations with public service provision was also included as citizens' expectations have frequently been tied to levels of satisfaction and trust in government $[31,37]$. Political affiliation and attitudes toward political leaders have also been found to be frame citizens' interpretations of the actions taken by their public sector $[87,88]$. Therefore, control variables for citizens' political affiliation and satisfaction with the mayor -support same party as mayor and citizens' satisfaction with mayor's leadership- are included in the model.

\section{Findings}

Table 2 shows the estimates from the simultaneous equation model that was used to assess the relationship between citizens' use of the online and offline information mediums for information about their government, citizen satisfaction with government information provision and citizen trust in government.

As is seen from Table 2, the variable of citizen satisfaction with government information provision is strongly correlated with citizens' trust in government, in both the OLS (column iii) and the 3SLS model (column iv). This robust relationship between satisfaction with government information provision and trust in government found by both the OLS and 3SLS models offer evidence to support hypothesis 1 ; citizens' higher levels of satisfaction with government information provision are suggested by the model to cause higher levels of trust in government.

In Table 2, columns (i) and (ii) illustrate the impact of citizens' use of different online and offline sources of information on their level of satisfaction with government information provision using estimates afforded by OLS (i) and simultaneous equation (ii) estimation methods. First, we look at the online medium. Interestingly, in the online medium citizens' use of the local government website was found to have no significant impact upon citizens' satisfaction with government information provision in either model. Regarding citizens' use of local government web media, this source was found to have a significant positive impact when estimated using OLS estimation methods but not in the estimates provided by 3SLS model. This means when accounting for the simultaneity, citizens' use of local government web media has no significant relationship with satisfaction with government information provision. Additionally, we see that citizens' use of private web media possessed no significant influence upon citizens' levels of satisfaction with government information provision in the OLS estimate, but possessed a significant negative influence in the 3SLS model Taken together, these findings suggest that government online sources of information are not associated with making citizens feel more or less informed regarding the activities of their government but non-government online sources of information are negatively related to satisfaction with government information provision, though the magnitude of the association is very small. 
Table 2. Simultaneous Equation Results.

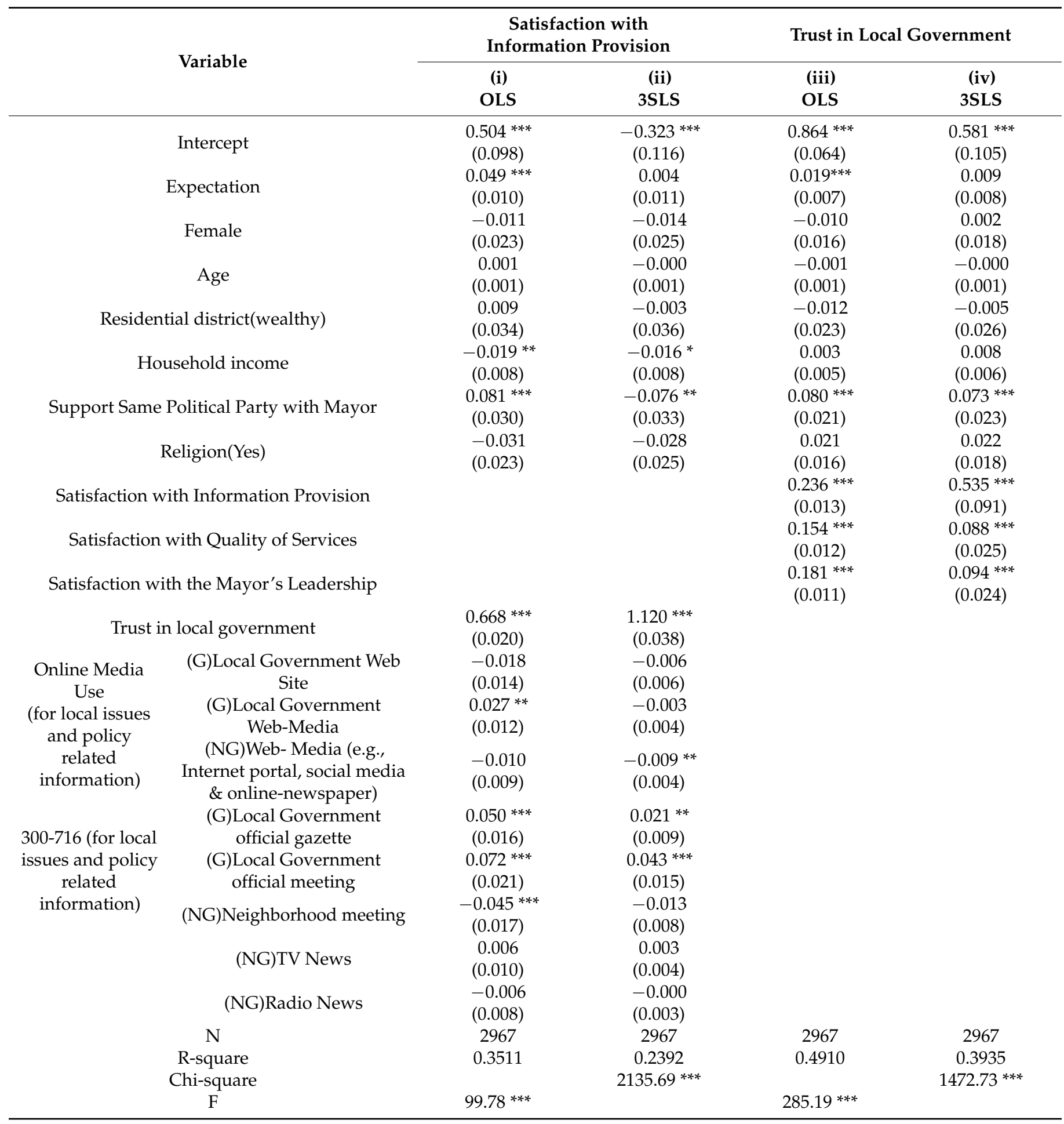

Note: ${ }^{* * *} p<0.01,{ }^{* *} p<0.05,{ }^{*} p<0.1 ;(\mathrm{G})$ refers to government sources, (NG) refers to non-government sources.

Turning to the offline sources assessed by this study, we find that both the OLS and 3SLS models suggest citizens use of the local government's gazette positively impacts citizens' satisfaction with government information provision. Citizens' attendance in local government town hall meetings was also found to positively impact their satisfaction with government information provision, in both the OLS and 3SLS models. Citizens' participation in local neighborhood meetings (not affiliated with government) were found to have a significant negative influence upon their satisfaction with government information 
provision in the OLS model but not in the 3SLS model. The other private offline media sources assessed in this study-TV and radio news- were not found to have a significant impact. Taken together, these findings offer evidence that suggests citizens' levels of satisfaction with government information provision are much more sensitive to information they acquire offline than to information acquired online. More specifically, citizens' levels of satisfaction with government information provision was consistently positively influenced by government offline sources of information, while private offline sources were found to have no significant influence.

\section{Discussion}

Table 3 presents the summary of finding. Evidence suggests that citizens' use of the government online medium has no significant relationship with satisfaction with government information provision, but citizens' use of the government offline medium has a positive association with satisfaction with information provision. By contrast, citizens use of non-government sources on the online medium has a negative relationship with satisfaction with government information provision. This means citizens' use of government sources on the online medium have no significant indirect relationship with trust in government, while their use of non-government sources online medium possesses a negative, though very small, indirect impact on the trust in government. On the other hand, citizens' use of government sources on the offline medium have a positive indirect relationship with trust in government, but their use of non-government sources on the offline medium have no significant association with trust in government.

Table 3. Summary of Findings.

\begin{tabular}{ccc}
\hline & Government Sources & Non-Government Sources \\
\hline Citizens' use of online medium & Not significant & Negative \\
\hline Citizens' use of offline medium & Positive & Not significant \\
\hline
\end{tabular}

Note: The relationship summarized here represent direct association with satisfaction with government information provision and indirect relationship with trust in government.

These findings are interesting because they challenge a rather prominent body of research that has argued the importance of government taking to the online medium as a means of connecting with citizens and positively affecting their perceptions and attitudes. Such arguments are premised upon the notion that government's use of the offline medium to connect with citizens was suboptimal; the government could do a better job at connecting with citizens, and the Internet was the way of doing so. However, the results of this research suggest just the opposite; citizens are more receptive to information they obtain via offline mediums, particularly with regard to information coming from their government.

Given the rapid expansion of information and communications technology over the past few decades, citizens' ability to inform themselves regarding government's activities is unparalleled when compared to previous eras in history [89,90]. As such, it is important for research to explore how such developments have affected the relationships between citizens and their government. Accordingly, this research examined how citizens' use of offline and online mediums for information about their government influenced their levels satisfaction with government information provision and consequently trust in government.

Based upon the theoretical framework, these results suggest that, given the amount of diverse information sources on the online medium, citizens tend to use the sources that align with their extant opinions on government, which in turn results in little substantive change to citizens' levels of satisfaction with government information provision. As such, citizens' use of the online medium may do little to change their attitudes and perceptions of government. By contrast, due to higher barriers to information dissemination on the offline medium citizens are exposed to information that may not necessarily align with their opinions on government, therefore creating the opportunity to facilitate some degree of change with respect to citizens' satisfaction with government information provision 
and trust in government. However, as Prior [91] has argued, it is extremely difficult for empirical research to quantify citizens' use and exposure to particular sources of information, either offline or online. As such, the explanation provided above constitutes one possible explanation for the results of this study, though other explanations are also possible. Perhaps most prominent among the alternative explanations relates to the degree of interactivity of the different mediums [92].

Implications from the findings of this research can be inferred. First, the potential of ICT and the Internet to transform citizens' relationships with their public services has encouraged a great deal of interest in ways of applying these new technologies to improve relationships between citizens and their public sector. However, the findings of this research, in addition to casting doubt upon the transformative potential of this new technology, encourages academics and practitioners alike not to devalue to utility of the offline medium for connecting with citizens as this medium remains very relevant in influencing citizens' attitudes toward their public sector. This is particularly the case for a city such as Seoul, whose public sector has invested heavily in cultivating the online medium as a means for improving relationships with citizens. As such, the findings of this research may be interpreted to suggest that, while governments attempt to shift public service provision to online and mobile formats it is also very important not to neglect the quality public service provision offline.

\section{Conclusions}

Based on our empirical assessment, this research has provided evidence that suggests citizens' frequency of use of the online medium had little direct impact upon citizens' levels of satisfaction with government information provision, and subsequently little impact upon citizens' trust in government. Conversely, this study has shown that citizens' increased use of the offline medium had a strong positive impact upon their satisfaction with government information provision and trust in government. Moreover, our analysis demonstrates that citizens' are more responsive to government sources of information accessed via the offline medium than they are government sources of information that are accessed via the online medium.

As mentioned earlier, in addition to the different number of information sources disseminating information on these mediums, online and offline mediums also differ in terms of their interactivity. A great deal of research has argued that the online medium is considerably less interactive when compared to the offline medium, particularly with respect of government sources. Therefore, an alternative explanation of the findings of this study is that the high interactivity of the offline medium evokes greater impacts upon citizens' levels of satisfaction with government information provision and trust in government than the less interactive online medium. However, it should be noted that all of the information sources used in this study, which together constitute the online medium all incorporate various tools intending to bolster their interactivity, ranging from comment boards to chatrooms to cyber town hall meetings. The city of Seoul has made considerable attempts to enhance the degree of interactivity of its websites, particularly about their urban sustainability initiatives $[93,94]$.

Finally, this study is not without limitations. While this study has found that citizens' use of offline and online mediums influence satisfaction with government information provision and trust in government differently, it is also possible, on empirical and conceptual grounds, that citizens' levels of trust in government influence their satisfaction with government information provision. While attempts were made to justify the approach taken in this research conceptually, as well as empirically through the use of a simultaneous equation model, a degree of caution should be exercised with respect to causal interpretations. Future research making use of experimental methodologies and different instrumental variables would be useful to substantiate the causal direction suggested by the findings of this study. This study also did not examine the interaction effects between online and offline sources of information, and future study needs to consider the modera- 
tors as individuals generally use both types of information. This article did not examine the hypothesized relationships by age groups while treat age just as control, while further investigation is needed as use of different platforms such as social media and other newly emerging online medium may have difference significance between generations such as millennials and generation $\mathrm{Z}$, as compared to baby-boomers or senior population.

Funding: No external funding.

Institutional Review Board Statement: IRB approval were waived for this study, as the data is secondary sources.

Informed Consent Statement: Not applicable.

Data Availability Statement: The data used in this paper is proprietary and raw data release is not permitted.

Conflicts of Interest: The authors declare no conflict of interest.

\section{References}

1. Jaeger, P.T. Deliberative democracy and the conceptual foundations of electronic government. Gov. Inf. Q. 2005, 22, 702-719. [CrossRef]

2. Brewer, G.A.; Neubauer, B.J.; Geiselhart, K. Designing and Implementing E-Government Systems: Critical Implications for Public Administration and Democracy. Adm. Soc. 2006, 38, 472-499. [CrossRef]

3. Im, T.; Cho, W.; Porumbescu, G.; Park, J. Internet, trust in government, and citizen compliance. J. Public Adm. Res. Theory 2014, 24, 741-763. [CrossRef]

4. Macintosh, A. Characterizing E-Participation in Policy-Making. In Proceedings of the Thirty-Seventh Annual Hawaii International Conference on System Sciences, Big Island, HI, USA, 5-8 January 2004.

5. Parent, M.; Vandebeeke, C.A.; Gemino, A. Building citizen trust through e-government. In Proceedings of the 37th Annual Hawaii International Conference on System Sciences, Big Island, HI, USA, 5-8 January 2004.

6. Tolbert, C.J.; Mossberger, K. The effects of e-government on trust and confidence in government. Public Adm. Rev. 2006, 66, 354-369. [CrossRef]

7. Morgeson, F.; VanAmburg, D.; Mithas, S. Misplaced trust? Exploring the structure of the e-government-citizen trust relationship. J. Public Adm. Res. Theory 2011, 21, 257-283. [CrossRef]

8. Van de Walle, S.; Van Roosbroek, S.; Bouckaert, G. Trust in the public sector: Is there any evidence for a long-term decline? Int. Rev. Adm. Sci. 2008, 74, 47-64. [CrossRef]

9. Chadwick, A.; May, C. Interaction between States and Citizens in the Age of the Internet: E-Government in the United States, Britain and the European Union. Gov. Int. J. Policy Adm. 2003, 16, 271-300. [CrossRef]

10. Gerodimos, R. Democracy and the Internet: Access, Engagement and Deliberation. Syst. Cybern. Inform. 2006, 3, $26-31$.

11. Shkabatur, J. Transparency with (out) accountability: Open government in the United States. Yale Law Pol'y Rev. 2012, 31. Available online: https://ylpr.yale.edu/transparency-without-accountability-open-government-united-states (accessed on 28 February 2021).

12. Grimmelikhuijsen, S. Transparency and Trust: An Experimental Study of Online Disclosure and Trust in Government. Ph.D. Thesis, University of Utrecht, Utrecht, The Netherlands, 2012.

13. Cucciniello, M.; Porumbescu, G.A.; Grimmelikhuijsen, S. 25 years of transparency research: Evidence and future directions. Public Adm. Rev. 2017, 77, 32-44. [CrossRef]

14. Im, T.; Lee, H.; Cho, W.; Campbell, J.W. Citizen preference and resource allocation: The case for participatory budgeting in Seoul. Local Gov. Stud. 2013, 40, 102-120. [CrossRef]

15. Mayer, R.C.; Davis, J.H.; Schoorman, D. An integrative model of organizational trust. Acad. Manag. Rev. 1995, $20,709-734$. [CrossRef]

16. Mabillard, V. Trust in Government: Assessing the Impact of Exposure to Information in a Local Context. Int. J. Public Adm. 2021. [CrossRef]

17. Rousseau, D.S.; Sitkin, R.B.; Camerer, C. Not so different after all: A cross discipline view of trust. Acad. Manag. Rev. 1998, $23,393-404$. [CrossRef]

18. Yamagishi, T.; Yamagishi, M. Trust and commitment in the United States and Japan. Motiv. Emot. 1994, 18, 129-166. [CrossRef]

19. Grimmelikhuijsen, S. Being transparent or spinning the message? An experiment into the effects of varying message content on trust in government. Inf. Polity 2011, 16, 35-50. [CrossRef]

20. Bouckaert, G.; Van de Walle, S.; Maddens, B.; Kampen, J. Identity vs. Performance: An Overview of Theories Explaining Trust in Government; Public Management Institute: Leuven, Belgium, 2002.

21. Lewis, J.D.; Weigert, A. Trust as a social Reality. Soc. Forces 1985, 63, 967-985. [CrossRef]

22. Becerra, M.; Gupta, A.K. Perceived trustworthiness within the organization: The moderating impact of communication frequency on trustor and trustee effects. Organ. Sci. 2004, 14, 32-44. [CrossRef] 
23. Jones, S.L.; Shah, P.P. Diagnosing the locus of trust: A temporal perspective for trustor, trustee, and dyadic influences on perceived trustworthiness. J. Appl. Psychol. 2016, 101, 39. [CrossRef] [PubMed]

24. Christensen, T.; Lægreid, P. Trust in government: The relative importance of service satisfaction, political factors, and demography. Public Perform. Manag. Rev. 2005, 28, 487-511.

25. Hupe, P.; Buffat, A. A public service gap: Capturing contexts in a comparative approach of street-level bureaucracy. Public Manag. Rev. 2014, 16, 548-569. [CrossRef]

26. Kim, D.; Cho, W. Labour-management relationships in fire services and basic labour rights of emergency responders. J. Soc. Sci. 2021, 32, 237-258. [CrossRef]

27. Ngich, L.; Cho, W. Addressing police corruption in Southeast Asia: Politics, participation, and public management reform. Public Adm. Issues 2020, 5, 9-34. [CrossRef]

28. Christensen, T.; Yamamoto, K.; Aoyagi, S. Trust in local government: Service satisfaction, culture, and demography. Adm. Soc. 2020, 52, 1268-1296. [CrossRef]

29. Heintzman, R.; Marson, B. People, service, and trust: Is there a public sector service value chain? Int. Rev. Adm. Sci. 2005, 71, 549-575. [CrossRef]

30. Cho, W.; Im, T.; Porumbescu, G.A.; Lee, H.; Park, J. A cross-country study of the relationship between Weberian bureaucracy and government performance. Int. Rev. Public Adm. 2013, 18, 115-137. [CrossRef]

31. Bouckaert, G.; Van de Walle, S. Comparing measures of citizen trust and user satisfaction as indicators of 'Good Governance': Difficulties in linking trust and satisfaction indicators. Int. Rev. Adm. Sci. 2003, 69, 329-343.

32. Uslaner, E. Trust, Civic Engagement, and the Internet. Political Commun. 2004, 21, 223-242. [CrossRef]

33. Porumbescu, G.A. Assessing the link between online mass media and trust in government: Evidence from Seoul, South Korea. Policy Internet 2013, 5, 418-443. [CrossRef]

34. Zhao, D.; Hu, W. Determinants of public trust in government: Empirical evidence from urban China. Int. Rev. Adm. Sci. 2017, 83, 358-377. [CrossRef]

35. Hood, C. What happens when transparency meets blame-avoidance? Public Adm. Rev. 2007, 9, 191-210. [CrossRef]

36. Morris, S.; Shin, H.S. Social value of public information. Am. Econ. Rev. 2002, 92, 1521-1534. [CrossRef]

37. Van Ryzin, G.G. Pieces of a puzzle: Linking government performance, citizen satisfaction, and trust. Public Perform. Manag. Rev. 2007, 30, 521-535. [CrossRef]

38. Halligan, J.; Sarrico, C.S.; Rhodes, M.L. On the road to performance governance in the public domain? Int. J. Product. Perform. Manag. 2012. [CrossRef]

39. Chanley, V.A.; Rudolph, T.J.; Rahn, W.M. The origins and consequences of public trust in government: A time series analysis. Public Opin. Q. 2000, 76, 239-256. [CrossRef] [PubMed]

40. Keele, L. Social capital and the dynamics of trust in government. Am. J. Political Sci. 2007, 51, 241-254. [CrossRef]

41. Kim, S.; Lee, J. E-participation, transparency, and trust in local government. Public Adm. Rev. 2012, 72, 819-828. [CrossRef]

42. Porumbescu, G.A.; Cucciniello, M.; Belle, N.; Nasi, G. Only hearing what they want to hear: Assessing when and why performance information triggers intentions to coproduce. Public Adm. 2020. [CrossRef]

43. Welch, E.W.; Hinnant, C.C.; Moon, M.J. Citizen Satisfaction with E-Government and Trust in Government. J. Public Adm. Res. Theory 2005, 15, 371-391. [CrossRef]

44. Pina, V.; Torres, L.; Royo, S. Are ICTs improving transparency and accountability in the EU regional and local governments? An empirical study. Public Adm. 2007, 85, 449-472. [CrossRef]

45. Swindell, D.; Kelly, J.M. Linking citizen satisfaction data to performance measures: A preliminary evaluation. Public Perform. Manag. Rev. 2000, 1, 30-52. [CrossRef]

46. Orren, G. Fall from grace: The public's loss of faith in government. In Why People Don't Trust Government; Harvard University Press: Cambridge, MA, USA, 1997; pp. 77-107.

47. Cho, W.; Ho, A.T.K. Does neighborhood crime matter? A multi-year survey study on perceptions of race, victimization, and public safety. Int. J. Law Crime Justice. 2018, 55, 13-26. [CrossRef]

48. Ho, A.T.K.; Cho, W. Government communication effectiveness and satisfaction with police performance: A large-scale survey study. Public Adm. Rev. 2017, 77, 228-239. [CrossRef]

49. Kang, Y.; Cho, W.; Jung, K. Does decentralization matter in health outcomes? Evidence from 22 OECD unbalanced panel data for 1995-2005. Int. Rev. Public Adm. 2012, 17, 1-32. [CrossRef]

50. Nye, J., Jr. Introduction: The decline of confidence in government. In Why People Don't Trust Government; Nye, J., Jr., Zelikow, P., King, D., Eds.; Harvard University Press: Cambridge, MA, USA, 1997; pp. 1-18.

51. Kampen, J.; Van de Walle, S.; Bouckaert, G. Assessing the relation between satisfaction with public service delivery and trust in government. Public Perform. Manag. Rev. 2006, 29, 387-404.

52. Gordon, M.T. Public trust in government: The US media as an agent of accountability? Int. Rev. Adm. Sci. 2000, 66, 297-310. [CrossRef]

53. Allen, B.; Tamindael, L.E.; Bickerton, S.H.; Cho, W. Does citizen coproduction lead to better urban services in smart cities projects? An empirical study on e-participation in a mobile big data platform. Gov. Inf. Q. 2020, 37, 101412. [CrossRef]

54. Cho, W.; Cha, S. Study of internationally-comparable indices of ICT development: Scope, measures, and limitations. Korean J. Public Adm. 2014, 52, 177-218. 
55. Nickerson, R.S. Confirmation bias: A ubiquitous phenomenon in many guises. Rev. Gen. Psychol. 1998, 2, 175-220. [CrossRef]

56. Frey, D. Recent research on selective exposure to information. Adv. Exp. Soc. Psychol. 1986, 19, 41-80.

57. Stroud, N.J. Media use and political predispositions: Revisiting the concept of selective exposure. Political Behav. 2008, 30, 341-366. [CrossRef]

58. Alon-Barkat, S. Can government public communications elicit undue trust? Exploring the interaction between symbols and substantive information in communications. J. Public Adm. Res. Theory 2020, 30, 77-95. [CrossRef]

59. Prior, M. Post-Broadcast Democracy: How Media Choice Increases Inequality in Political Involvement and Polarizes Elections; Cambridge University Press: Cambridge, UK, 2007.

60. Mutz, D.C.; Martin, P.S. Facilitating communication across lines of political difference: The role of mass media. Am. Political Sci. Rev. 2001, 1, 97-114. [CrossRef]

61. Entman, R.M. Projections of Power: Framing News, Public Opinion, and U.S. Foreign Policy; The University of Chicago Press: Chicago, IL, USA, 2004.

62. Mathews, J.T. Power Shift. Foreign Aff. 1997, 76, 50-66. [CrossRef]

63. Prior, M. The immensely inflated news audience: Assessing bias in self-reported news exposure. Public Opin. Q. 2009, 73, 130-143. [CrossRef]

64. Hur, J.; Kwon, M.; Cho, W. Administrative inefficiency of geographically dispersed central government bodies: Case study on Sejong City in Korea using grounded theory. Korean Public Adm. Rev. 2015, 49, 127-159. [CrossRef]

65. Lee, T.; Lee, B.K.; Lee-Geiller, S. The effects of information literacy on trust in government websites: Evidence from an online experiment. Int. J. Inf. Manag. 2020, 52, 102098. [CrossRef]

66. Porumbescu, G. Linking transparency to trust in government and voice. Am. Rev. Public Adm. 2017, 47, 520-537. [CrossRef]

67. Kim, N.; Cho, W. Agencification and performance: The impact of autonomy and result-control on the performance of executive agencies in Korea. Public Perform. Manag. Rev. 2014, 38, 214-233. [CrossRef]

68. Porumbescu, G.; Jungho, P.; Oomsels, P. Building trust: Communication and subordinate trust in public organizations. Transylv. Rev. Adm. Sci. 2013, 9, 158-179.

69. Cho, W. Change and continuity in police organizations: Institution, legitimacy, and democratization. Korean J. Policy Stud. 2017, 32, 149-174. [CrossRef]

70. Kim, M.H.; Cho, W.; Choi, H.; Hur, J.Y. Assessing the South Korean model of emergency management during the COVID-19 pandemic. Asian Stud. Rev. 2020, 44, 567-578. [CrossRef]

71. Choi, H.; Cho, W.; Kim, M.H.; Hur, J.Y. Public health emergency and crisis management: Case study of SARS-CoV-2 outbreak. Int. J. Environ. Res. Public Health 2020, 17, 3984. [CrossRef] [PubMed]

72. Porumbescu, G.A. Comparing the effects of e-government and social media use on trust in government: Evidence from Seoul, South Korea. Public Manag. Rev. 2016, 18, 1308-1334. [CrossRef]

73. Wirtz, B.W.; Birkmeyer, S. Open government: Origin, development, and conceptual perspectives. Int. J. Public Adm. 2015, 38, 381-396. [CrossRef]

74. Hur, J.Y.; Cho, W.; Lee, G.; Bickerton, S.H. The "smart work" myth: How bureaucratic inertia and workplace culture stymied digital transformation in the relocation of South Korea's capital. Asian Stud. Rev. 2019, 43, 691-709. [CrossRef]

75. Schuetze, T.; Chelleri, L. Urban sustainability versus green-washing: Fallacy and reality of urban regeneration in downtown Seoul. Sustainability 2016, 8, 33. [CrossRef]

76. Kim, D.; Cho, W.; Park, H. Asset-building approaches to community development and the role of local government in urban regeneration. Korean J. Public Adm. 2019, 28, 85-119.

77. Wooldridge, J. Econometric Analysis of Cross Section and Panel Data; Massachusetts Institute of Technology: Cambridge, MA, USA, 2004.

78. Greene, W. Econometric Analysis; Prentice Hall: Upper Saddle River, NJ, USA, 2008.

79. Russel, C.; Bobko, P. Moderated Regression Analysis and Likert Scales Too Coarse for Comfort. J. Appl. Psychol. 1992, 77, 336-342. [CrossRef]

80. Owuor, C.O. Implications of Using Likert Data in Multiple Regression Analysis. Ph. D. Thesis, Simon Frasier University, Burnaby, BC, Canada, 2001.

81. Owuor, C.; Zumbo, B. Implications of ordinal scale categorization on regression models under different distributions and conditions. In Proceedings of the NCME Conference, Seattle, WA, USA, 12 April 2001.

82. Citrin, J. Comment: The political relevance of trust in government. Am. Political Sci. Rev. 1974, 68, 973-988. [CrossRef]

83. Job, J. How is trust in government created? It begins at home, but ends in the parliament. Aust. Rev. Public Aff. 2005, 6, 1-23.

84. Cook, T.K.; Gronke, P. The skeptical American: Revisiting the meanings of trust in government and confidence in institutions. J. Political 2005, 67, 784-803. [CrossRef]

85. Goldfinch, S.; Gauld, R.; Herbison, P. The Participation Divide? Political Participation, Trust in Government, and E-Government in Australia and New Zealand. Aust. J. Public Adm. 2009, 68, 333-350. [CrossRef]

86. Lewicki, R.J.; McAllister, D.J.; Bies, R.J. Trust and distrust: New relationships and realities. Acad. Manag. Rev. 1998, $23,438-458$. [CrossRef]

87. Morgeson, F.; Petrescu, C. Do They All Perform Alike? An Examination of Perceived Performance, Citizen Satisfaction, and Trust with US federal agencies. Int. Rev. Adm. Sci. 2011, 77, 451-479. [CrossRef] 
88. Miller, A.H. Political issues and trust in government: 1964-1970. Am. Political Sci. Rev. 1974, 68, 951-972. [CrossRef]

89. Sagarik, D.; Chansukree, P.; Cho, W.; Berman, E. E-government 4.0 in Thailand: The role of central agencies. Inf. Polity 2018, 23, 343-353. [CrossRef]

90. Porumbescu, G.A.; Piotrowski, S.J.; Mabillard, V. Performance Information, Racial Bias, and Citizen Evaluations of Government: Evidence from Two Studies. J. Public Adm. Res. Theory 2021. [CrossRef]

91. Prior, M. The challenge of measuring media exposure: Reply to Dilliplane, Goldman, and Mutz. Political Commun. 2013, 30, 620-634. [CrossRef]

92. Wallsten, K. Agenda Setting and the Blogosphere: An analysis of the Relationship between Mainstream Media and Political Blogs. Rev. Policy Res. 2007, 24, 567-587. [CrossRef]

93. Kim, D.; Cho, W.; Allen, B. Sustainability of social economy organizations (SEOs): An analysis of the conditions for surviving and thriving. Soc. Sci. J. 2020. [CrossRef]

94. Wang, B.; Park, S.D.; Lee, J.Y.; Campbell, J.W. Smart, Sustainable and Citizen Centered: A Network Analysis of Urban R\&D Trends in Seoul, South Korea. Sustainability 2020, 12, 5933. [CrossRef] 